\title{
Chapter
}

11

\section{Strengthening of the Sociotechnical Approach in Information Systems Research}

\author{
Isabel Cafezeiro, José Viterbo, Leonardo Cruz da Costa, Luciana Salgado, \\ Marcelo Rocha, Rodrigo Salvador Monteiro
}

\begin{abstract}
The contemporary world shows evidence that the form of understanding of science and technology strengthened over the modern era has been failing to follow the agile, dynamic and heterogeneous mechanism in which contemporary society establishes its relations and its modes of operation. The rigidity of scientific approaches is strongly supported by pre-set categories and disciplines. When faced with the dynamism of society, this often causes conflict and endangers the effectiveness of research. Hence, we argue in favor of a sociotechnical approach as a mechanism to better understand knowledge construction and to enlarge the possibilities of concretization of the research in all fields of knowledge, and, in particular, in the field of Information Systems.
\end{abstract}

\subsection{Introduction}

The sociotechnical approach ${ }^{1}$ seeks ways of building knowledge to be able to move in the several configurations that life presents us. This cuts across disciplinary boundaries, and does not suit a fixed language or a pre-established methodology. One must learn to be always reinventing. This is the sociotechnical challenge: learning to be in constant flux to enable productive work at the frontiers of knowledge fields.

While those may seem rather vague words, the field of Information Systems shows us how urgent and concrete this approach is: information systems are spread across our lives; are present in the most unexpected corners and cause profound changes in our way of living and understanding of life. From this diversity of contexts in which a system may act some questions arise and we address them here:

\footnotetext{
${ }^{1}$ In this paper, the terms "sociotechnical" and "socio-technical" have different meanings, as explained in Section 11.2.
} 
- How to train a professional to build systems capable of operating in the various contexts?

- What skills and knowledge are required to carry out research to provide answers to contemporary requests?

\subsection{Context}

These issues have already been perceived by the active academic community of Information Systems in Brazil. For example, analyzing the challenges and possibilities of research in this field in Brazil, Cidral et al (2009) pointed out in "Information Systems in Brazil - Challenges and Opportunities" the need to open "the multi/inter/transdisciplinary; the continuous exercise of applied research to industry, government or society problems, in a truly integrated and joint way; and the characterization of the professional profile of a graduate degree in Information Systems, in line with the demands of industry and market". Six years later, researchers working in the implementation of electronic medical records warned (when debating the Grand Challenges in Information Systems): "If it were a matter of technique, the electronic medical record would already be in operation for a long time!" It is not a coincidence that we find two chapters in this book proposing different ways of addressing the same problem: the ineffectiveness of research in the face of life's impediments. What is missing to allow the Brazilian patients to access their health information records? What is missing to allow our research to come effectively into operation?

We argue that it is missing to take into account the sociotechnical network of which we are part. This exposes the many and various reasons that come into play in the execution of our research proposals. It is missing to relate the "technical knowledge" that we claim to have, and the knowledge considered to be "of other types", which includes, among others, the humanities. In order to understand the society, we live in and being able to deal with what we now consider "the most unforeseen issues", we need to improve our skills in relating the most diverse fields of knowledge and operate with them.

The inefficiency of systems that are often designed in isolation from the environments in which they operate and the little resourcefulness of professionals who seek to act on "strictly technical basis" have made us long to overcome the assumption that the technique alone would enable us to build systems that are sufficiently flexible, able to meet the demands of our time. As computing is a field that claims its place among the exact sciences (or at least that is thus classified in the tables of the Brazilian research funding agencies such as CNPq and Capes) we came to believe that looking straight to international technical standards we would invent correct and reliable systems. Adherence and fidelity to such standards captured our minds as much as they closed our eyes to the world we live in.

We soon realized that when we invent and configure the systems, we also invent and configure the users, defining their preferences and ways of acting [Woolgar 1991]. And along with the user, we also invent all the rest: a complex world, the environment that should host the system and enable operation. Therefore, the moment the system is put into operation used to reveal the most disastrous surprises, putting us in front of a user-world that we did not imagine. The world very rarely behaved as our systems expected. For this, the world would have to be committed to the process of co-invention: system-user-environment engaged throughout the whole design process. 
Hence, we found ourselves facing the challenge of (re)knowing the world, which implies interacting beyond our expertise. At a first moment, this highlighted our lack of preparation and our refusal to deal with issues that we consider "subjective" or "humanistic", that is, everything that seems to move away from the technical scope. We reacted and began to consider the presence of different knowledge in training. We comforted ourselves in the certainty that the socio-technical approaches (social knowledge + technical knowledge) would bring the world back, and thus avoid the unexpected conflicts that had encumbered the operation of our systems. New curricula for bachelor degrees in Information Systems have emerged, in which technical and humanistic disciplines co-exist. This is the scenario today, and from this several research proposals have arisen with socio-cultural commitment.

However, a conflict emerged that gave visibility to a deeper cultural issue: the gap between the two cultures, exact and humanistic [Latour 2014]. The disciplinary presence of humanistic knowledge, did not actually lead (or led only tentatively) to the construction of common concepts derived from the dialogue between the parties. It did not enable the invention of the world-system nor favor the construction of productive fields to stimulate the meeting and interaction of technical and humanistic knowledge.

A general scenario of dissatisfaction emerged, revealed in several ways:

- In learning, the enormous difficulties in understanding the contents of disciplines considered technical, which causes failure in alarming rates, and even the dropping out. Along with this, the depreciation of the humanistic part, generally considered "easy and unnecessary".

- In research, the difficulty in establishing interdisciplinary research programs because of the academic overvaluation of publications centered in the field of computation, and a certain misunderstanding of the differences between applied research and interdisciplinary research (in the former, an asymmetrical relationship, in which a field provides facilities or services to another, in the latter, co-operation: building a common conceptual apparatus able to solve problems and address issues of both fields). Also concerning research, the persistence of the difficulties of effecting in society the research results.

- Finally, concerning work, the difficulty in training professionals able to respond with ease to dialogue needs and the increasing flexibility of the contemporary world. This is a key to the development of appropriate information systems.

Given this situation, what is our challenge?

Here we propose a quite different approach based on the non-recognition of the division between technical knowledge and humanities. The undermining of this division is supported by the deconstruction of the notions of "essence", "origin" and "purification" of knowledge. This gives visibility to the evidence that knowledge is socially constructed. It is thus committed with time and place, as well as with the power relations that are configured at this time and place [Shapin 2010]. From this, we reject methods and models that are supported by interferences between a supposed "technical world" and a supposed "social world". We reject structured, systemic approaches. The sociotechnical approach is supported in the comprehension of the historical paths of construction of knowledge, giving visibility the interweaving of knowledge 
and things of life and avoiding classifications such as the technical-social and nature-social divisions.

\subsection{The Sociotechnical Challenge}

Here we propose the challenge of a hybrid approach that can only be identified by a neologism: sociotechnical (without hyphen), a word that means that in addition to recognizing specialties and their interdependencies it is necessary to develop the ability to carry over the differences between them. This is the ability that the Information Systems professional must have to be productive in very different situations: in the dynamics of events this professional must work in the encounter between technical and social. It is a new approach to research: no longer to "make systems for the most diverse areas". The sociotechnical proposal is to "make systems with the most diverse areas". As proposed by Bernardes, Tavares and Moraes (2004) to "research with" society and the labor market.

The starting point for this is to assume a place of speech, that is, to make it clear not only who is speaking, but also when, where and why he speaks [Foucault 1972]. The concept of place of speech is important to highlight the inadequacy of disconnecting the subject of the discourse and the event in which the discourse was conceived [Foucault 1996]. Sociotechnical research demands a situated approach [Haraway 1988] regarding the time and place where it is enunciated. Here we see that the prospects of neutrality and universality of the modern conception of science do not meet the demands of the sociotechnical project because it does not promote the direct dialogue with society. Moreover, the sociotechnical proposal goes contrary to the aims of impartiality of modern science. It is strongly committed to its time and place. It is therefore necessary to seek a repositioning of the researcher with respect to the issue it addresses.

Let us return to the major research challenges in computing from the decade 2006-2016 [SBC 2006] to illustrate this repositioning, and see how the sociotechnical approach can contribute to the practice of research, following the dynamics of contemporary society. We will see that, although most of these challenges relate to issues considered technical, almost all proposals are supported by justifications that are considered to belong to the social field. This is not surprising since all knowledge production, even that considered to be exclusively technical, only finds meaning in life and for life, and life is society. José Mujica, former president of Uruguay, expressed this in a few words, during his visit to Brazil to receive the Medal of Inconfidence:

(...) we are social. No one can live alone. We need a cardiologist, a mechanic, a teacher for our son. We need someone to drive the bus, someone who support us in life, a midwife at birth and a gravedigger when we die. (Part of the speech of José Mujica on April 21, 2016, Minas Gerais)

What is surprising, however, is that as soon as the challenge is recognized as important to society (in the justifications), the researcher turns his/her back to society and focuses strictly on the technique (the goals), and from this point on, there is no place left for the social. 
In the decade of 2006-2016, SBC pointed out five major challenges: 1. Information management of distributed multimedia data in large volumes; 2 . Computational modeling of complex systems: artificial, natural and sociocultural and human-nature interaction; 3 . Impacts caused to the computing area by the transition from the silicon computer to new technologies; 4. Participative and universal access for Brazilian citizens to knowledge and 5. High quality technological development: available, accurate, secure, scalable, persistent and ubiquitous systems.

From these, only the third challenge is not justified on social grounds, relying on technical arguments to convince the reader the need for theoretical and practical researches to support the transition from silicon to modern technologies. Regarding the other four challenges, the social question appears explicitly in the fourth, in the title of the second, and predominates in the examples and justifications of the first and fifth. However, the research efforts presented in the text of each challenge are predominantly technical. This shows a clear division between the social and the technical. Society occupies the role of a beneficiary (passive, just receives the action), but offers little or no collaboration in building its own benefits. This would be a task for the technique. This scene reflects the perspective of "research for", but not "research with" [Bernardes, Tavares and Moraes, 2004] because it seeks to escape from the encounter between the society and the researcher.

A sociotechnical approach is configured in "research with", a repositioning: to recognize the place of the other to operate in the meeting of both. This is a hybridity of knowledge throughout the process, deconstructing the idea that the technique is the only way to achieve social progress. This same division between the technical and social is evident in the justifications (social) and goals (technical) of each challenge. The sociotechnical approach helps to harmonize justifications and goals, as it is the dialogue between the technical and social issues. It facilitates co-operation (operating together) of knowledge in its construction process. Therefore, since research has its moment of realization in society, the sociotechnical approach helps to increase the chances of successful enterprises.

Within the ten years envisioned in the Grand Challenge proposal many students in our classrooms will be working as researchers in the information systems field, this is why the fulfillment of a sociotechnical challenge starts in the classroom and continues in the profession. Therefore, we must pay attention to the coherence between the classroom practices and the proposals taught today about the development of systems and professional practices. For example, there is no point in arguing that systems should be made in a dialogic relationship with the user [Beck et al, 2001], [Wells, 1999] if the classroom environment is authoritarian, antidialogical, and a place where the teacher is the sole source of knowledge. Similarly, the arguments in favor of a freedom in the exercise of the profession are weakened when they come from an academic community that supports regulatory practices of teaching. In the following, we situate the sociotechnical challenge considering contemporary settings regarding society, education and profession.

\subsubsection{Contemporary Society and the Sociotechnical Challenge}

Since the start of the twenty-first century, Europe has been shocked by the arrival of refugees from the Middle East, North Africa and south of the Sahara. They are fleeing from the miseries 
of war and famine. They deterritorialize: go beyond borders. The strength of this exodus terrifies the established powers. They arrive by the thousands daily. It is a movement of deconstruction, where not only territorial borders are questioned, but borders of another kind: limits in access to citizenship. In Brazil, this century has also moved crowds. In 2016, popular carnival blocks such as "Galo da Madrugada", in Recife, or "Bola Preta", in Rio, dragged millions. Shortly before, in 2013, the increase in bus fares led no less than 1.25 million people to take to the streets in various parts of Brazil on a single day: June $20^{\text {th }}$. At that time, the rise in bus fares was given as reason for the demonstration, but a closer look revealed a diverse agenda, overflowing the boundaries of a single and immediate issue, a multiplicity of claims.

From this global phenomenon of questioning borders, we will argue that the scenario of computer systems follows the mechanisms of society. For example, the presence of the crowd, their hybrids and their dynamics, is clear in the field of computing. Hence there is a need for research investment to re-situate the development strategies of systems to better accommodate the contemporary mode of operation.

As in society, in the field of information systems, a crowd is not uniform, but a multiplicity, decentered, which acts to deconstruct borders, to put in check firmly established issues. A clear example is the shift of the control and decision focus in information systems. Previously, this was a prerogative of algorithms, now, it is subject to the becomings of the crowd, thus strengthening a contrast with Al-based solutions that go in the opposite direction of taking decision power and action from people to inferring and deciding for them. These new strategies of control and decision shift the crowd from the position of consumers to that of producers (not only of content) in recent systems of crowdsourcing and human computation [Ahn et al. 2004], [Ahn et al. 2008].

These trends that are now so clearly shown in various contexts followed (and were followed by) modes of thought that arose in the 1970s [Latour, 1994] when postmodern intellectuals presented alternative ways of thought. This means an alternative path to the totalizing, universal, neutral, linear, pure and rational claims of modern thought.

When we say "totalizing" we are referring to the modern scientific view that wants to embrace a whole field of knowledge. The movements of foundations of mathematics of the first decades of the twentieth century are a clear manifestation of this way of thinking, particularly the formalist movement proposed by David Hilbert to ensure consistency, completeness and decidability of the whole mathematics [Cafezeiro, Haeusler, Marques, Cukierman, 2010].

When we say "universal" we are referring to formulations that allegedly could be applied anywhere, independent of the social and cultural settings of each location. By "neutral" we refer to the understanding that the formulations do not carry with them any trace of the place and time where they were conceived and nor personal understanding of who enunciated. By "linear" we mean the concepts that take an evolutionary character, excelling linearly along the timeline, and in this path, disregarding the many redoings and interferences of several factors. By "pure" we refer to the conceptions expressed on disciplinary boundaries. Finally, by the term "rational" we refer to those conceptions that are claimed to be exclusive products of the intellect. 
In short, the research in interaction with society puts in check these six qualities of the four precepts of logic of the scientific method of Descartes [Descartes, 2001], a seminal milestone in the modern understanding of science.

\subsubsection{The current situation of academic teaching and the sociotechnical challenge} These ideas explored by intellectuals of the 1970s were not only perceived in intellectual and scientific circles, but they were also developed in co-construction with the arts, reaching the media, and infiltrating society. Young people who now sit in our classrooms, were born and grew up after the 1970s, that is, they are the children of this postmodern society. Their way of thinking and operating questions the rigidity of modern categorizations and claims the flow, multiplicities, the decentralization and flexibilization of the borders. Thus, we witness the restlessness to know how to relate curriculum and work, profession and life. Students seek something new, challenging what is established. They are participatory and work well together. Moreover, operating in multiple media at the same time, they do not need to complete a task before starting another and they usually obtain surprising results in what they want to do. This set of characteristics contrasts dramatically with their school grades. Complaints by the teaching staff have become commonplace, usually suggesting that the alleged "failure" of the student is due to the low quality of their high school or admission to university through social programs. However, for some of these students, academic inflexibility and the distance of themes and content regarding social dynamics are often unbearable, often leading to some students dropping out.

The modus operandi of academia has not been adapting fast enough for the changes that have been taking place in society. It offers young people an academic education characterized by well-defined borders: the classroom organized around a central figure, the lecturer, physically located in a position from where he/she supposedly emanates knowledge. A curriculum that ignores local identities and subjectivities and is tied on a fixed list of contents; a knowledge categorized in areas, technical and humanistic, which, at the same time reflect and determine the spatial organization of campuses. Academic activities divided into teachingresearch-extension categories, which are united only in the text of the Brazilian Constitution, but not in academic practice. The division teaching-research-extension also reflects and determines the bureaucratic structure of the rectories and the division of funds. This is a scene of a university disconnected from the market and industry. Given this conflicting picture, it is not surprising that situations that had already been identified as problematic at the end of the last century have now acquired an untenable dimension. They can be directly measured and visible through dissatisfaction, dropping out, retention and the revolt of both students and teachers.

\subsubsection{Regulatory policies of the profession and the sociotechnical challenge}

The great adherence of the academic community to disciplinary matters, a conception of teaching that is very focused on a rigid classroom dominated by the authority of the lecturer, and the non-critical obedience to curricular content is reforced by the representative entity, the Brazilian Computer Society (SBC), by the adoption of a reference curricula and minimum content for disciplines based on international models of the ACM (Association for Computing Machinery) and the AIS (Association for Information Systems). Standardization policies for courses to achieve the quality that is envisioned in standards set worldwide are adopted. An alternative 
way would be to support and encourage the curriculum proposals developed in the localities, and to consider parameters of success and quality with a view to these local initiatives.

However, with regard to the profession, we see within this same community the call for flexibility and dynamic, yet expressed in socio-technical terms, based on the observation of a multidisciplinary approach. For example, the law project 1561/2003, where the SBC stands as community spokesman, ascribes to multidisciplinarity the importance of avoiding the compulsory formal education for the exercise of the profession and rejects the imposition of regulatory boards:

\begin{abstract}
Unlike other areas of human knowledge, Informatics permeates in a deep and evident way almost all areas of human knowledge. To resolve problems with suitable level of quality, in addition to technical knowledge of Information Technology, the professional must have competence in the areas of specific application, whether engineering, medicine, business, music, etc. If at first the multidisciplinary vocational training was a direct consequence of the lack of higher education courses in Information Technology, it is now a requirement to meet the demand of society for new and increasingly sophisticated applications. And multidisciplinary approach is built on the fertile grounds of freedom of professional practice. (Justifications of the PL 1561/2003, http://www.camara.gov.br/proposicoesWeb/fichadetramitacao?idProposic $\underline{\mathrm{ao}=126039}$ )
\end{abstract}

Here we see that the sociotechnical challenge is still misunderstood. The demand for multiple knowledge is acknowledged, but the separation between the technical knowledge of computers and other forms of knowledge in the various fields is clearly emphasized. Computing is presented here as an area to provide services to other areas through the construction of information systems, and not as an area that is built in the encounter with others. Finally, there is a contradictory separation between the rigidity of the mode of operation in academia and the longed-for freedom to practice the profession.

\title{
11.3.4. The research in computing and the sociotechnical challenge
}

In the field of research, the history of the construction of the Information Systems field Cafezeiro, Costa, Kubrusly [2016a] shows the demand for a sociotechnical approach.

At the end of World War II, the Cold War made it clear that the techniques by themselves would not meet the demand of sudden changes and quick responses required by the scenario of this new war. There arose the need for a science which would not be accomplished in the field of exact knowledge and not even in the humanities, but in the meeting of both. The mathematician Norbert Wiener coined the term "cybernetics" to refer to the sciences of border areas, a new field that would treat information in multiple views [Wiener 1985].

Later, mainly due to the discussions in conferences promoted by NATO in 1968 and 1969 [Nato 1968], [Nato, 1969], Computer Science was configured on the choice of a disciplinary science within a mathematical base. At that time, the voices against this choice were not strong enough to counteract the mathematization of Computer Science. Their understanding of computation based on "information" was a clear demand for hybrid knowledge. Only a few decades later, the diversity of fields with which the computer systems would interact again 
brought into the foreground the need for interaction with various areas. This showed the impossibility of fulfillment of the demands from a knowledge confined to the field of Computer Science. The curricula of Information Systems emerged, differing from the Computer Science curricula by a socio-technical perspective. The adherence to Computer Science explains why the practice in research in Information Systems is still predominantly disciplinary often disregarding the sociotechnical approach.

Today the field of Information Systems is receptive to interdisciplinary conceptions. The main reason is that information systems incorporate and give visibility to these issues of contemporary society, and therefore there is a need to understand the social dynamics and cooperate (operating together) with it. Moreover, it is a recent science whose institutionalization has occurred in a hybrid form. It is a young field, which, like the students who attend our classes, was born and raised in the wake of a dynamic, agile, flow and hybrid society. Therefore, the achievement of the sociotechnical approach is a challenge for the next decade. This means creating possibilities to operate on the border of the categories which are still shown dichotomous and isolated. Information systems can capture and respond to demands flow, dynamism and diversity of the society. Surpassing the very borders of the field of Information Systems, this learning may contribute to propose new teaching and learning concepts, new ways to accomplish the construction of interdisciplinary knowledge, spread by the various fields of knowledge [Cafezeiro, Costa \& Kubrusly 2016b].

\subsection{Background}

As for research in Information Systems in Brazil, the sociotechnical challenge relates to the evolution of the understanding of sociotechnical studies that have arisen in the field of Software Engineering [Cukierman 2007]. This has a start point in the socio--technical approach that is based on the demarcation between the technical and the non-technical (this latter, would be the social) and proceeds in arguments based on the overlapping of these areas.

These discussions are supported by the Actor-Network Theory (ANT), which is a widespread practice in Rio de Janeiro [Araujo and Valente 2014]. The concept of 'translation' [Law 1977] provides a way to make the methods that are supposed to be strictly followed more flexible. It argues for the possibility of re-signifying knowledge according to the demands of its use. The same author also proposes the term "ontological politics" that help (re)building (re)frameworks, demonstrating that reality does not precede the mundane practices, on the contrary, it is performed from them [Mol 1999].

The Actor-Network Theory places us in the position to challenge established practices and the imposition of the hegemonic approaches, to eventually propose new ways that best suit Brazilian research needs. The reference [Bijker and Law 1992], Bijker 1995] deals directly with the sociotechnical approach, and Woolgar (1991) brings the issue into the field of users and usability. Other concepts already mentioned in this text contribute to the sociotechnical proposal to the extent that they claim adherence to time, space, event, subject, and avoid the universal approaches (those that are presented as if they were "of nowhere", or what has the same effect, "of everywhere"). The concept of "place of speech" that can be found in Foucault (1972), Foucault (1996), and the proposal of situated approach of [Haraway 1988] are in tune with ANT. 
Regarding contemporary practice in the classroom and contemporary approaches to the profession, we refer to the proposal of Gary Downey for engineering studies in the US, called "critical participation" [Downey 2009]. Downey's proposal is inspired by the work of Gramsci (1999).

In Brazil, the approach presented here has its foundation and inspiration in the educational proposals of Paulo Freire $[1985,1987]$. Issues related to the sociotechnical approach in exact sciences are discussed in [Cafezeiro, Costa, Kubrusly 2016a].

At the Federal Fluminense University, the sociotechnical challenge is also adopted in the field of psychology in the proposal "research with" [Bernardes, Tavares, Moraes 2004]. These studies argue for a change in the researcher's stance with respect to the group related to the research seeking rapprochement, dialogue and co-construction, in the same way as the current trends in systems development argue for a constant rapprochement between user and designer.

\subsection{Progress Evaluation}

We list below some parameters that may indicate the evolution of the sociotechnical approach, reducing the gap between categories that today are firmly grounded in academic practice. We take as example the trajectory of the course of Information Systems of the Federal Fluminense University:

- Shortening the distance between technical and humanistic disciplines, making the dialog between them effective

- Promoting this dialogue also within disciplines considered of the technical scope.

- Basing the teaching in the flow of dialogue and debate, as opposed to supporting the teaching on the presentation of program content

- Approximating academia and the labor market by encouraging the operation of junior companies and the participation of entrepreneurs from the information technology field in the classroom, discussing the profession and market practices together with students

- Making the dialogue between teacher and student effective seeking a more participatory classroom

- Encouraging research and creation at all levels, increasing the participation of graduate students in research projects

- Working on the demand of local problems as opposed to prioritizing fixed issues, universally attributed to the area of Information Systems.

In terms of the progress evaluation of this proposal, we have seen that the most recent disciplines of Information Systems courses tend to incorporate the sociotechnical approach more easily. The greatest difficulties are in the disciplines of early training such as introduction to programming, data structures, mathematics, and some inherited disciplines of Computer Science which adopt standards considered universal or unquestionable, or that are too submissive to the models of success of the developed world. The adoption of a sociotechnical approach in these contexts involves considering the construction process of each subject, topic, result or method, to make visible the participation of the society in the formation of concepts, formulas or methods. This means leaving apparent that the process of construction of sciences is situated, that is, related to a time and place [Sawyer and Jarrahi 2014]. In addition, it is important to bear in mind that the process of construction of sciences is always committed to certain interests. Therefore, the effectiveness of the research is facilitated when the links 
between the addressed topic and its environment of enunciation (who-when-how-where) are explicitly addressed.

It should be emphasized that, from its beginning, the field of Information Systems shows a clear demand for the sociotechnical approach. This can be perceived by the presence of sociotechnical actors (people, society, organizations, other sources of knowledge) in the relevant problems of the field. Hence, the progress evaluation of this approach can be observed by the ease with which the sociotechnical challenge is received in its intended environments.

- Computer systems directly show the demand for a sociotechnical approach when computers require human processing to carry out their tasks (the field of human computation).

- Computer systems already incorporate culture as a key element in the construction of their interfaces, and more, today we realize that culture is reflected in the very architectural arrangement of computer systems.

- Ubiquitous systems that spread imperceptibly in our daily life only achieve success when they can capture the environment of social dynamics where they intend to operate.

- The organization of large data volumes (mining) and the organization of large volumes of work (outsourcing) require the behavioral and cultural understanding of the place where it will be supplied or used.

- Organizations now recognize the importance of other skills in addition to technical ones. This can be noted in the current forms of the dynamics of recruitment and selection of human resources, as well as in efforts and investment in work strategies in collaborative groups.

- The proliferation of social networking in specific areas, at work, at school, in family or for fun, makes the importance of interaction and collaboration clear in different situations of life.

- The need to expand participatory access to Brazilian citizens, as well as the construction of public policies for science, technology, society and innovation, and the deployment of applications to support public policies (e-learning, e-government, electronic support scientific research, medical electronics) require the observation of cultural and social issues to the same degree as technical requirements.

- The transition from competitive social paradigm for collaborative is performed in the relationship between the different areas, and therefore dialogue between these areas. Hence, the need to undo the gap between the two cultures: the world of technology and the social world.

\subsection{Final Remarks}

In very general terms, the sociotechnical challenge lies in destabilizing borders that today are still very rigidly established because it is in this hybrid space between the usual categories that one can realize the dynamics of the contemporary society operating in constant changes, permanently remaking itself. The sociotechnical challenge in Information Systems is to follow the flow in society, perceiving that solutions to the demands of society never exclusively belong to a single domain or discipline.

What should be done in the field of research? Researchers should be aware that without establishing in fact a constant dialogue with our society, their research will tend not to produce the desired effect. This is because, for several reasons that are not in the scope of technique, these researches are prevented from going into operation. The way to establish this dialogue is 
to understand the modus operandi of contemporary society to make it possible to negotiate with it. This requires adopting a situated practice [Haraway 1988] of research, where society is present and participating in the entire process, and not only in the justifications.

This is an issue that is becoming increasingly clear for system developers. They now realize that involving the users only at the initial and final phases of the development process increases the chances of impediments and inadequacies in the implementation of systems. Similarly, the Information Systems community is realizing that keeping society isolated in justifications of research makes it difficult, or even impossible to achieve the desired results.

\section{References}

Ahn, L., Blum, M., Langford, J. (2004) "Telling Human and Computers apart". Communications of the ACM Vol. 47, N. 2, p.58-60.

Ahn, L., Maurer, B., McMiller, C. Ahn, D., Blum, M. (2008) "reCAPTCHA: HumanBased Character Recognition via Web Security Measure”. Science v. 321.

Araújo, J. F. M.; Valente, C. M., (2014) Ator-Rede e além... no Brasil: as Teorias que aqui gorjeam não gorjeam como lá?, (In Portuguese) Ed. da Univ. Est. da Paraíba, Campina Grande. (In Portuguese)

Beck et al (2001) "Manifesto for Agile Software Development". Available at: $<$ http://www.agilemanifesto.org $>$. Accessed on 07/26/2017.

Bernardes, A. G., Tavares G. M. \& Moraes, M. (2004) Cartas para pensar políticas de pesquisa em psicologia, EdUFES, Vitória. (In Portuguese)

Bijker, W. E. \& Law, J. (1992) - Shaping Technology/Building Society: Studies in Sociotechnical Change, Cambridge, Massachusetts, The MIT press.

Bijker, Wiebe E. (1995). Of bicycles, bakelites, and bulbs: toward a theory of sociotechnical change. Cambridge, Massachusetts, The MIT press.

Cafezeiro, I.; Haeusler, H.; Marques, I.; Cukierman, H. (2010) "Recontando a Computabilidade". Rev. Br. de Hist. da Ciência, Rio de Janeiro, v. 3, n. 2, p. 231-251. (In Portuguese)

Cafezeiro, I., Costa, L. C. \& Kubrusly, R. (2016a) "Modos contemporâneos de aprendizado e construção do conhecimento: reflexões sobre o ensino de Teoria da Computação para Sistemas de Informação", In: Anais do CSBC-WEI, p. 2245-2254, PUCRS. (In Portuguese)

Cafezeiro, I., Costa, L. C. \& Kubrusly, R. (2016b) "Ciência da Computação, Ciência da Informação, Sistemas de Informação: Uma reflexão sobre o papel da informação e da interdisciplinaridade na configuração das tecnologias e das ciências", In: Perspectivas em Ciência da Informação, v1, n3, p.111-133, jul/set. (In Portuguese)

Cidral, A., Ralha, C., Cárceres, E., Santoro, F., Audy, J., Barros, M., Furtado, O., Araújo, R. (2009) "Sistemas de Informação no Brasil - Desafios e Oportunidades", Comitê Gestor do Simpósio Brasileiro de Sistemas de Informação, SBC. (In Portuguese)

Cukierman, H. L.; Teixeira, C.; Prikladnicki, R. (2007) Um olhar sociotécnico sobre a engenharia de software. In: Rev. de Inf. Teórica e Aplicada, RS, UFRGS. (In Portuguese)

Descartes, R. (2001) O Discurso do Método. Ed. Martins Fontes. São Paulo. (In 
Portuguese)

Downey, G. (2009) "What is Engineering Studies For? Dominant Practices and Scalable Scholarship", Engineering Studies: Journal of the International Network for Engineering Studies 1(1):55-76.

Foucault, M. (1972) A Arqueologia do Saber. Petrópolis, Vozes. (In Portuguese)

Foucault, M. (1996) A Ordem do Discurso, São Paulo, Edições Loyola. (In Portuguese)

Gramsci, A. (1999) "The Organisation of Education and of Culture". In Q. Hoare \& G. N. Smith (Eds) Selections from Prison Notebooks: On Education (1929-1935). Available at: $\quad<$ http://www.walkingbutterfly.com/wp-content/uploads/2010/12/ gramsci-prison-notebooks-vol1.pdf $>$. Accessed on Accessed on 07/26/2017.

Haraway, D. (1988) "Situated Knowledges: The Science Question in Feminism and the Privilege of Partial Perspective". Feminist Studies, Vol. 14, No. 3. p. 575-599.

Latour, B. (1994) Jamais fomos modernos, Editora 34, Rio de Janeiro. (In Portuguese)

Latour, B. (2014) "Scientific Humanities, Introduction", Available at:

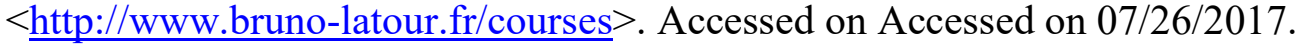

Law, J (1997) “Traduction/Trahison: Notes On ANT", published by the Department of Sociology, Lancaster University. Available at: <www.comp.lancs.ac.uk/sociology/ papers/law-traduction-trahison.pdf $>$. Accessed on Accessed on 07/26/2017.

Mol, A. (1999) "Ontological politics. A word and some questions". In: The Sociological Review, vol 47, p. 75-89.

Nato (1968) Report of a conference sponsored by the NATO Science Committee. Garmisch, Germany, 7-11 Oct. 1968. Brussels: Scientific Affairs Division; NATO 1969. Available at: <http://homepages.cs.ncl.ac.uk/brian.randell/NATO/ nato1968.pdf $>$. Accessed on 07/26/2017.

Nato (1969) Report of a conference sponsored by the NATO Science Committee. Rome, Italy, 27-31 Oct. 1969. Brussels: Scientific Affairs Division, NATO, 1970. Available at: $<$ http://homepages.cs.ncl.ac.uk/brian.randell/NATO/nato1969.pdf $>$. Accessed on Accessed on 07/26/2017.

Shapin, S. (2010) "Never Pure: historical studies of science as if it was produced by people with bodies, situated in time, space, culture and society, and struggling for credibility and authorithy". The John Hopkins University Press, Baltimore.

Sawyer, S. \& Jarrahi, M. H., (2014) "Sociotechnical Approaches to the Study of Information Systems". In: Information Systems and Information Technology. Eds: Tucker, A., Gonzales, T., Topi, H., Diaz-Herrera, J., Chapmann and Hall, p.1-27.

SBC, (2006). Grandes Desafios da Pesquisa em Computação no Brasil - 2006-2016. Relatório Sobre o Seminário Realizado em 8 e 9 de Maio de 2006. (In Portuguese)

Wells, D. (1999) "Extreme Programming". Available at: $<$ http://www.extremeprogramming.org $>$. Accessed on Accessed on 07/26/2017.

Wiener, N. (1985) Cybernetics or control and communication in the animal and the machine. Cambridge, MA: The MIT Press.

Woolgar, S. (1991) "Configuring the user: the case of usability trials", In: A Sociology of Monsters: Essays on Power, Technology and Domination, Ed. Law, J., New York. 


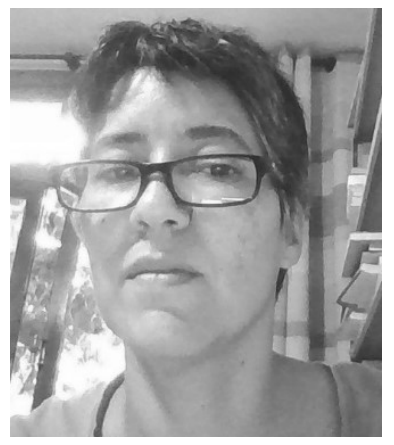

\section{Isabel Cafezeiro}

CV: http://lattes.cnpq.br/7610075482763248

DSc in Computing, Isabel Cafezeiro is an associate professor at the Computer Institute at the Federal Fluminense University in the State of Rio de Janeiro (UFF). Her research interests are Information Systems, Sociotechnical approach, Social Studies of Science and Technology, focusing primarily on the history of computability and researches on academic work. e-mail:

isabel@dcc.ic.uff.br

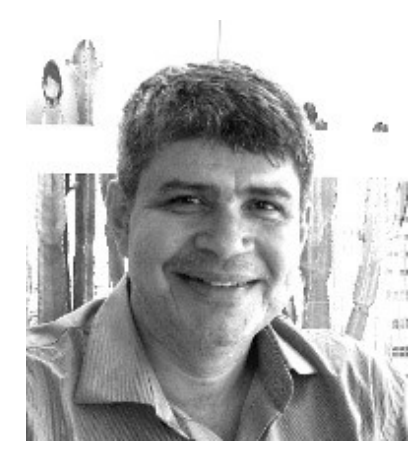

\section{José Viterbo}

CV: $\underline{\text { http://lattes.cnpq.br/8721187139726277 }}$

DSc in Computer Science, José Viterbo is a lecturer at the Institute of Computing, Fluminense Federal University (IC/UFF). He coordinates the Laboratory of Real-Time Systems and Embedded Systems (LabTempo) and is an associate researcher at the Laboratory of Active Documentation and Intelligent Design (ADDLabs) and Laboratory of Management in Information and Communication Technology (GTecCom), at the same university. He is the Director of Publications of the Brazilian Computer Society (SBC) and a member of the UFF Graduate Program in Computer Science (PPGC/UFF). His main research interests include ubiquitous computing, distributed inference, open data, knowledge representation and big data. e-mail: viterbo@ic.uff.br

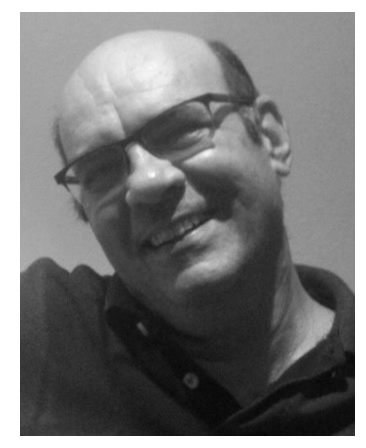

\section{Leonardo Cruz da Costa}

CV: http://lattes.cnpq.br/4355227997824234

DSc in Information Science, Leonardo Cruz da Costa is an associate professor and researcher at the Federal Fluminense University (UFF) in the State of Rio de Janeiro. Currently is coordinator of the Information Systems course (UFF). He is a member of the UFF Graduate Program in Information Science (PPGCI/UFF), where he conducts research in the area of semantics, text mining and knowledge representation. e-mail: leo@dcc.ic.uff.br 


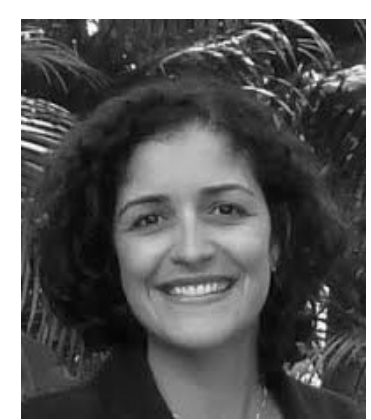

\section{Luciana Salgado}

CV: http://lattes.cnpq.br/9126192988265844

DSc in Informatics from PUC-Rio. Her professional experience includes several years (from 1993 to 2004) as systems developer coordinator and as business intelligence analyst. She currently continues her research in the field of Human-Computer Interaction (HCI), as seen from a Semiotic Engineering perspective, and in IT Governance, at Federal Fluminense University (UFF), Rio de Janeiro, Brazil. Her current research interests involve semiotic accounts of Culture in HCI and IT Governance and topics that contribute to expand and refine Semiotic Engineering Theory and Methods. She is, currently, Adjunct Professor at UFF. e-mail: luciana@ic.uff.br

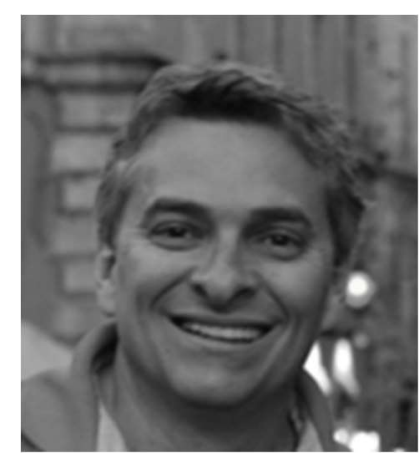

\section{Marcelo da Costa Rocha}

Graduated in Computer Science, Marcelo is founder of F2C Consulting, an IT company focused on Oracle Technology. His research interests are: Information Systems, Sociotechnical approach, Social Studies of Science and Technology, focusing primarily on social transformation by use of technology and innovation.

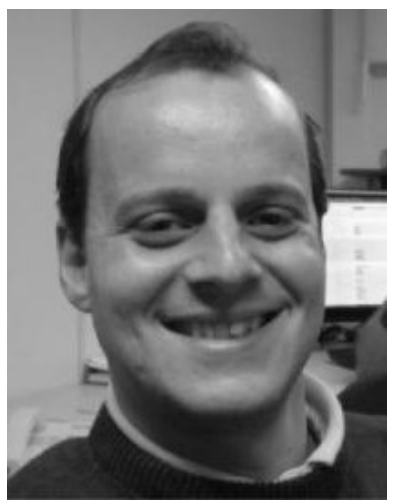

\section{Rodrigo Salvador Monteiro}

CV: http://lattes.cnpq.br/0023809873085852

DSc in Computer and Systems Engineering, Rodrigo Salvador Monteiro is an adjunct professor and researcher at the Federal Fluminense University (UFF) in the State of Rio de Janeiro. His research interests are: Model Driven Architecture (MDA), Spatial Databases, Data Warehouse and Information Systems. email: salvador@ic.uff.br 